\title{
Instructional Practices for Addressing Computer Science Standards: Using Computer Kits in Preservice Teacher Education
}

\author{
Gamze Ozogul ${ }^{\text {a }}$, Michael Karlin ${ }^{\mathrm{b}}$, Anne Ottenbreit-Leftwich ${ }^{\mathrm{c}}$, Ai-Chu Elisha Ding \\ d, Yin-Chan Liao ${ }^{\text {e }}$, Meize Guo ${ }^{\mathrm{f}}$ \\ ${ }^{a}$ Indiana University, US, gozogul@indiana.edu ORCID: 0000-0002-8044-9021 \\ ${ }^{b}$ Indiana University,US, mkarlin@indiana.edu ORCID:0000-0002-3600-2513 \\ ${ }^{c}$ Indiana University,US, aleftwich@indiana.edu \\ ${ }^{d}$ Ball State University, US, ading@bsu.edu \\ e University of Chicago,US, liao33@uchicago.edu ORCID: 0000-0001-8854-7809 \\ ${ }^{f}$ Indiana University, US, guo30@indiana.edu ORCID: 0000-0002-3013-964X
}

\begin{abstract}
This article examines the instructional practices used to teach the computer science (CS) standard of computer devices and systems to undergraduate preservice teachers (PSTS). With computer science education (CSE) gaining an international focus, there is a need to explore a variety of instructional practices used to teach these topics. This descriptive, exploratory case study presents an examination of the instructional practices used in a CSE licensure course. In this study, the instructor utilised two commercially available computer kits to provide hands-on, learnercentred learning experiences for PSTs. PSTs perceived these kits to be valuable for learning about computing devices and systems topics and for teaching these topics in their future classrooms. Additionally, results showed that PSTs considered the usability, grade level and ability of the kits to build interest in CS when reflecting on their future use. Limitations to the instructional practices included a lack of transfer to subject areas outside of CS and a lack of focus on the integration between hardware and software.
\end{abstract}

Keywords: Computer Science Education, Preservice Teacher Education, Computing Devices and Systems

\section{Introduction}

Computer science education (CSE) is gaining an international focus. In the past few years, many countries have implemented computer science (CS) curricula and/or standards (e.g., Ireland, UK, Sweden) (Hubwieser et al., 2015). This is also true for the United States, and many K-12 stakeholders have suggested that CS skills are necessary for today's students. For example, both the Obama administration (The White House, 2016) and the Trump administration (The White House, 2017) emphasised the importance of CSE and proposed multiple initiatives to support CSE at the national level. Furthermore, the US Bureau of Labor Statistics (2018) suggested that 58\% of all new science, technology, engineering and mathematics (STEM) jobs will be in CS. In addition to initiatives from industry and government, many US states have attempted to address the concern for CSE by adopting CS standards in elementary, middle and high schools to graduate students equipped with CS skills (Code.org, 2018). According to Code.org's 2018 report, 22 out of 50 US states had implemented K-12 CS standards, with an additional ten in progress. As this study took place in the state of Indiana, we further describe the Indiana CS standards in the following to provide context. 


\section{Instructional Practices for Addressing Computer Science Standards: Using Computer Kits in Preservice Teacher Education \\ Ozogul, Karlin, Ottenbreit-Leftwich, Ding, Liao, Guo}

\section{CS Standards for Indiana}

In 2016, the state of Indiana adopted K-8 CS standards (Indiana Department of Education, 2019). These standards were broken into five strands: (1) Data and Information, (2) Computing Devices and Systems, (3) Programs and Algorithms, (4) Networking and Communication and (5) Impact and Culture. The standards were based on the US national K-12 CS Framework (K-12 Computer Science Framework, 2016), which was created in collaboration with the Association for Computing Machinery (ACM), Code.org, the Computer Science Teachers Association (CSTA), the Cyber Innovation Center (CIC) and the National Math and Science Initiative (NMSI).

For this article, we have narrowed our focus to the strand of Computing Devices and Systems, specifically the topics of hardware and software. We found this area to be important because perceptions of CS have often been limited to the topics of programming or computational thinking (Webb et al., 2017). Other state standards have also emphasised the importance of including hardware and software within a complete CS curriculum (e.g., Massachusetts) (Massachusetts Department of Elementary and Secondary Education, 2016).

In Indiana, to teach hardware and software, teachers typically need to be certified with a CS license. This license is an add-on to the four-year preservice teacher (PST) degree. In addition to an initial license area (e.g., math, English, elementary), PSTs take four additional courses and complete six weeks of practicum teaching to add-on this license and become certified to teach CS (e.g., Ozogul, Karlin, Ottenbreit-Leftwich, 2018). Not only in Indiana, many other states across the country have recognised the importance and need of preparing PSTs for CSE to meet the demand for qualified teachers to teach CS in K-12 schools (Delyser, Goode, Guzdial, Kafai, \& Yadav, 2018). Meanwhile, continuing to research ways to teach and prepare K-12 CS teachers is necessary (Yadav, Sands, Good, \& Lishinki, 2018). Therefore, the purpose of this study was to examine instructional practices that could be used to teach PSTs the topics of hardware and software in a CSE course.

\section{Methods}

This study used a descriptive, exploratory case-student design (Yin, 2017) to examine the instructor rationale and student perspectives of an activity designed to cover the topic of Computing Devices and Systems, with a specific focus on hardware and software. We relied on two data sources: (1) instructor interview and (2) student reflections. The analysis of these two data sources allowed us to answer the study's two research questions:

Research Question 1: What instructional practices were used to teach PSTs the topic of Computing Devices and Systems, and what was the instructor's rationale for these instructional practices?

Research Question 2: What were PSTs' perspectives of the value of these instructional practices in preparing to teach the topic of Computing Devices and Systems in their future classrooms?

\section{Context}

This study took place at a large university's school of education (SOE) within Indiana. Elementary and secondary PSTs within this SOE had the option of earning an add-on license to teach CS (Ozogul, Karlin, Ottenbreit-Leftwich, 2018). Participants of the study were the course instructor and the 12 PSTs enrolled in the CS licensure course. The course instructor had previously taught the course twice. However, this was the first time he was teaching the topic of Computing Devices and Systems using the instructional practices that were the focus of this study. Most of the PSTs enrolled in the course were to become elementary school teachers (n9), while three planned to become secondary teachers (n3). All PSTs were in their last year of their undergraduate programs, and 11 were female and one was male.

This study took place while preparing PSTs to teach hardware and software to their future students. The instructional practices used to deliver the lesson occurred over two- to three-hour classes. The instructional objectives of the lesson were to address hardware and software topics such as parts of a computer, the interaction between hardware and software, the installation of an operating system, as well as the paedagogical approaches for delivering this content in the future. These objectives were addressed through the use of two computer kits and their included curricula: Piper and Kano, both of which are commercially available and marketed towards K-12 students and classrooms.

\subsection{Computer Kits Overview and Curricula}

At the time of the study, the Kano curriculum included a 145-page document that explained the overall paedagogical approach and addressed Computer Devices and Systems topics over 17 lessons. Overall, the Kano curriculum focussed on six topics: (1) hardware, (2) software, (3) program development, (4) control, (5) algorithms and (6) variables. The Kano curriculum guided the users through a journey inside a computer system. The user controlled a character to explore different worlds, represented by different hardware components. 


\section{Instructional Practices for Addressing Computer Science Standards: Using Computer Kits in Preservice Teacher Education \\ Ozogul, Karlin, Ottenbreit-Leftwich, Ding, Liao, Guo}

The Piper curriculum consisted of five sets of presentation slides and a 23-page document. The curriculum was focused on Computing Devices and Systems topics such as circuitry, buttons, inputs and outputs and switches. Piper was entirely based on Minecraft and guided users through a series of missions in a specific order. As users worked through the missions, they continued the process of building their computer kit.

\subsection{Procedures}

PSTs were assigned to build either a Piper kit (n5) or a Kano kit (n7). PSTs completed a pre-reflection form before beginning to work with their assigned kit (Appendix A). Each student was asked to use the instructions provided with the kits to assemble their computer. On average, the Kano kits took between 10 and 15 minutes to assemble, while the Piper kits took between 45 and 60 minutes to assemble. Once the kits had been assembled, the students used the curriculum to explore their kit. Since the Kano kits took less time to assemble, the PSTs who reviewed the Kano kit had more time to explore the curriculum.

During the curricular exploration, PSTs were asked to consider the value of the assigned kit and curriculum from the perspective of a classroom teacher asked to teach hardware and software. While exploring the kits, the instructor asked the PSTs to focus on the benefits and limitations of both the kits and the provided curriculum. This exploration of the kits and curriculum took the first three-hour class period. PSTs took notes and reflected on the assigned questions throughout the process, which they used during the second three-hour class period.

During the second three-hour class period, PSTs were put in groups of two with peer(s) who had explored the other kit. This was designed to be a microteaching experience where the PSTs could practice teaching with the kits they had been assigned. During the first 90 minutes, the students who had built the Piper kit explained their process for building the kit, walked their partner through the curriculum and discussed the benefits and limitations they discovered. Afterwards, the groups switched, and the PSTs who had built the Kano kits walked their partner through the same process. At the conclusion of this class period, students completed the post-reflection form (Appendix B).

\section{Data Sources and Analysis}

To answer the two research questions, we conducted an instructor interview and collected student reflections.

\subsection{Instructor Interview}

For the first research question, we conducted a 50-minute, online, semi-structured interview with the instructor to understand why he decided on this curricular approach. Seven questions were asked during the interview centred on the instructor's description and rationale of his CS course design and instructional practices.

\subsection{Student Reflections}

For the second research question, we collected PST pre- and post-reflection forms (Appendices A and B) that were focused on their experiences with the lesson and the kits.

\subsection{Analysis}

The interview and reflections were analysed using thematic analysis (Braun \& Clarke, 2006) to identify emerging themes aligned with the research questions. Two researchers coded each data source separately and then later discussed the codes together. In cases of disagreement, the two researchers discussed until agreement was reached (Saldaña, 2015). During this discussion, the two researchers finalised the codes and brought them to the research team for a final discussion to determine the emergent themes. For the interview, the transcript and emergent themes were with the instructor to increase validity.

\section{Results}

In this case study, we sought to examine the instructional practices while teaching hardware and software to PSTs in a CSE course by using readily available kits. Below are the results of the two research questions 


\section{Instructional Practices for Addressing Computer Science Standards: Using Computer Kits in Preservice Teacher Education \\ Ozogul, Karlin, Ottenbreit-Leftwich, Ding, Liao, Guo}

\subsection{Research Question One}

Instructional Practices. The instructor indicated that the primary instructional practice for this lesson was the use of hands-on, learner-centred experiences. Based on the instructor's past experience, he described that hands-on, learnercentred approaches were the most effective way to teach these topics. He explained, "I used kits because I wanted something that was hands-on, learner centred, available in their future jobs, and offered a curriculum. Plus, I wanted our PSTs to microteach to reflect on how they might teach these topics in their future classroom". He continued: "I wanted to find authentic activities, that could be applied in authentic contexts, where students worked collaboratively, and reflected on their work".

To make the learning experience more applicable in future instructional settings, the instructor asked his students to reflect on their experiences with the kits and the microteaching from the perspective of a future teacher. He reported that the "microteaching experiences helped our PSTs articulate the benefits and limitations of the kits, and helped them frame their learning experience from the perspective of a teacher who would be potentially using these types of kits to teach".

Rationale for Instructional Practices. The primary rationale reported by the instructor was a need to address Computing Devices and Systems topics. Based on the instructor's interview, the aforementioned instructional practice was used to meet the course objectives as and the CS standards for PST licensure. For example, the instructor stated that the need to focus on Computing Devices and Systems standards came from both the state and national levels: "These standards are at the state level for Indiana, but also if you're looking at any CS national standards or frameworks, they're there as well". As one of the requirements for teacher education programs is to prepare PSTs to teach the state CS standards in their future classrooms, this was also a consideration.

Beyond the standards, the instructor noted that these skills were foundational for CS understanding: "hardware and software are just fundamental to how a computer works". However, he also expressed an awareness that PSTs lacked this fundamental knowledge and needed more exposure during his class: "part of what our future teachers should be able to teach are the hardware and software standards, and from my own experiences, these are often overlooked or ignored". Because of this, the instructor designed this activity to focus on "using these kits and their associated curriculum to help PSTs understand the basics of hardware, how hardware interacts with software, and the overall basic interactions between all computer components".

\subsection{Research Question Two:}

In PSTs' post-activity reflections, there were four categories of emergent themes related to the perceived value of implementing similar kits in their future classrooms. These four categories are presented in the following.

Future Usability of the Computer Kits. Before considering the value of the kits for addressing Computing Devices and Systems topics, the PSTs first considered the general future usability of the kits. The usability aspects included time required, ease of use, cost, troubleshooting, and support. First, time required referred to how long it took PSTs to build and explore the kit and whether the amount of time spent was worth the learning gains reached. For example, one elementary PST who worked with Piper reflected: "Piper was cool to build but creating the box [for the kit] took up a lot of time ..." (P6, Q1-UT). Another elementary PST who tried Kano pointed out that there were multiple glitches to overcome in Kano and fixing these glitches would take away from instructional time if she were to use in his/her future classroom (P10, Q2-UG).

Second, ease of use was another emergent theme from PST's reflections. This was an important consideration for elementary PSTs, since they will work with young children who are still developing complex thinking competencies. For example, one elementary PST compared the ease of use between Piper and Kano and reflected: "Since I want to teach second grade, I feel like the Kano computer set would be more beneficial. It's easier to set up and it goes through more step-by-step instructions which would be helpful for those younger kids" (P9, Q3-EOU).

The third emergent theme from the post-reflection analysis was related to the cost of the kit. The two computer kits used in this study costed more than $\$ 100$ each. Therefore, when PSTs were asked whether they would use the assigned computer kit in their future classroom, one PST responded: "Unsure - I think there are less expensive, more costeffective options to teach [these topics]" (P2, Q5-UM). Another PST reflected that it would depend on "how much money can be used to fund the computer sets and whether the school is a STEM school or not" (P9, Q1-UM).

The fourth emergent theme from the post-reflection analysis was related to the value of the curriculum that was bundled with the kits. Overall, the PSTs thought that the lesson plans and curriculum would help save planning time. For example, one PST pointed out that she would be willing to adopt Piper as a result of the curriculum: "I like the slides that came with Piper. They help teach concepts that are often hard to explain" (P12, Q4-VC). Another PST who tried Kano wrote in the post reflection: "I think the [curriculum] provided for Kano would be helpful because they have thorough lesson plans" (P8, Q4-VC).

The last emergent theme related to the future usability of the kits was the availability of the companies' troubleshooting and support services. PSTs recognised that technical issues were an inevitable part of teaching CS, and 


\section{Instructional Practices for Addressing Computer Science Standards: Using Computer Kits in Preservice Teacher Education}

Ozogul, Karlin, Ottenbreit-Leftwich, Ding, Liao, Guo

therefore, they also cared about the troubleshooting and support available to them when reflecting on the future usability of these kits. For example, one elementary PST compared Piper and Kano in terms of both their curriculum and troubleshooting services in the post reflection: "The piper had good lesson plans, but not very helpful for troubleshooting. The Kano lessons were very lengthy and sometimes overwhelming but provided good support" (P5, Q4-TS).

Learning about Computing Systems and Devices. A second category of emergent themes from post-activity reflections related to the value of the kits being beneficial for learning about Computing Devices and Systems standards. Both kits required users to assemble parts together to create a functioning computer, and therefore, PSTs perceived this as a valuable experience for learning about hardware and software. For example, one PST mentioned: "I think [the Kano kit] helped me to see the separate parts of the computer" (P11, Q2-CSD). Another PST reflected: "I think [the Piper kit] teaches [students] all about a computer, and what a computer has in it, as well as steps for how it is built" (P6, Q2-CSD). Therefore, the PSTs thought both kits were helpful with learning the hardware aspects of computer devices and systems. In terms of learning the hardware and systems aspects of CS, PSTs expressed a preference towards Piper more often as it was perceived "easier to use".

Characteristics of Future Learners. In addition to considering usability and the ability to address Computing Devices and Systems standards, PSTs considered if these kits would be beneficial based on the age and grade level of students in the PSTs' future classrooms. For example, one PST wrote: "it is important to think about what age group could actually work with the different kits" (P5, Q1-UA). A secondary-level PST stated that Piper would be more appropriate for her future classroom because it is a "complex task for the older students" (P2, Q3-UA). An elementary PST wrote about the Piper kit that "it could be too difficult for elementary students" (P8, Q2-UA), and another reflected that with the Piper, "the students need some serious help and scaffolding" (P8, Q2-US) and that the kit was "above students' understanding” (P12, Q2-UD). Overall, the PSTs perceived that the Piper kit might be better suited for older learners, whereas the Kano kit would be better suited for younger learners.

Building Interest in CS. Finally, PSTs considered the importance of engagement and building interest in CS when considering the use of these kits to teach hardware and software in their future classrooms. Based on PSTs' reflections, there were two emergent themes related to how these computer kits may build future students' interest. The first theme was that these kits taught hardware and software through gameplay and storytelling. For example, one PST wrote: "Piper is way more interactive. There's a story for the kids to get into and motivate them" (P8, Q3-STR). Another PST reflected: "I would use Kano because the story feature goes through and tells a very simple story about the different elements of computer hardware that are easy to understand" (P5, Q7-STR).

The second theme related to the hands-on nature of the activity. For example, one elementary PST wrote: "It's rewarding for the students to build it themselves and see the product as well" (P8, Q2-HSO). Another PST wrote about the connection between learning with computer kits and students' daily experiences with technology. This elementary PST noted: "I feel like it allows students the opportunity to learn the mechanics behind a machine that they use daily. I feel like the students will begin to appreciate how much effort and time needs to go into creating a computer" (P6, Q2HSO).

\section{Discussion}

This study investigated the instructor's instructional practices and rationale for choosing hands-on, learner-centred computer kits to teach CS standards related to hardware and software. This study also captured PSTs' perceptions of the value of this instructional practice and the perceived value for the future use of similar kits. The findings of this study suggested that the instructor and PSTs found this activity valuable for learning about hardware and software, even though they noted some limitations. In the following are mentioned areas that may need further consideration while adapting similar instructional practices.

Missing Integration of Hardware and Software. In addition to being able to teach hardware and software as separate topics, PSTs must have an understanding of the integration between hardware and software. In other words, PSTs must be able to teach about how these two topics interact with each other (e.g., BIOS, Operating Systems). Based on the PST reflections and the instructor interview, this was not a topic that was successfully addressed through this activity. No PSTs reflected on the interaction between hardware and software, and the instructor noted in his interview that "I think my PSTs have gained a better understanding of both hardware and software from this activity. However, based on my observations of their microteaching, and through their reflections, I do not believe they have a firm understanding of the interaction between hardware and software". One limitation to this study was the limited time (two three-hour class periods), and it is possible that the integration between hardware and software would have been more thoroughly addressed given more time.

Lack of Transfer to Other Subject Areas. For some PSTs, especially those in secondary education, there was a struggle to identify how to use these kits in their future subject areas to address content area standards. For example, a secondary English language arts (ELA) PST wrote: "I don't think it would be beneficial in a high school ELA 
classroom because it would not cover any of the standards I'd need to teach". On the other hand, one secondary PST who also found the kits not relevant to content area teaching reflected: "I do not see the kits relating to my curriculum and standards. I think it would be more beneficial in a computer class". While K-8 teachers in Indiana are now required to address CS standards, this is usually done in a stand-alone CS class at the middle and high school levels. This struggle to make connections to their future classroom might also be due to a lack of paedagogical content knowledge (e.g., Shulman, 1986). However, all students enrolled in this course were also enrolled in the computer education licensure program and therefore required to be able to address these standards for licensure purposes.

Next Iteration of the Activity. Based on the experiences described in this study, the instructor significantly revised this activity for the following semester. The instructor described in his interview that "rather than use the Piper and Kano computer kits, I wanted to invite a local expert to bring in multiple computers in order for the students to disassemble them and learn about the various components". The instructor continued: "this provided the students with an opportunity to see more complex computers, as the Piper and Kano kits are both Raspberry-Pi based, and do not include all of the components of a more traditional computer". Based on the discussion point above about the lack of integration between hardware and software, the instructor also noted that "I made it a specific point to spend more significant time not just learning about the different computer components, but also discussing with our guest speaker how all these components interacted with each other, and with their associated software". With these revisions, the instructor reflected: "I think this next iteration went well in terms of reaching the learning objectives, but I don't believe it was as engaging for the students as the Piper and Kano kits". An additional revision might focus specifically on the development of paedagogical content knowledge, which Yadav and Korb (2012) argue is essential for PSTs to develop in order to successfully teach CS. Yadav and Korb (2012) proposed a CS methods course in teacher education to provide classroom observations and microteaching opportunities combined with reflections for PSTs to "think, know, feel, and act like a teacher" (p. 33). This also aligns with suggestions from instructional design literature on teaching and learning in higher education (e.g., Biggs, 1996). These types of additions might further help PSTs to develop connections to their future classrooms, which, as noted earlier, was a struggle.

\section{Conclusion}

As CS standards continue to be adopted across the US and other countries, it is important to investigate various instructional practices and their effectiveness for addressing these standards. While programming and coding are often the focus of CS, it is also beneficial to explore best practices for teaching hardware and software CS standards. Finally, it is crucial to investigate how we prepare our future CS teachers with the CS knowledge and paedagogy they need so that they can better prepare the next generation of students with CS skills, knowledge and interest.

\section{References}

Biggs, J. (1996). Enhancing teaching through constructive alignment. Higher Education, 32(3), 347-364.

Braun, V., \& Clarke, V. (2006). Using thematic analysis in psychology. Qualitative Research in Psychology, 3, 77-101. https://doi.org/10.1191/1478088706qp063oa

Bureau of Labor Statistics. (2018). Employment by major occupational group, 2016 and projected 2026. Retrieved from: https://www.bls.gov/emp/ep_table_101.htm

Code.org. (2018). 2018 State of Computer Science Education. Retrieved from https://advocacy.code.org/

Delyser, L. A., Goode, J., Guzdial, M., Kafai, Y., \& Yadav, A. (2018). Priming the computer science teacher pump: Integrating computer science education into schools of education. CSforAll, New York, NY.

Hubwieser, P., Giannakos, M. N., Berges, M., Brinda, T., Diethelm, I., Magenheim, J.,Pal,

Y.Jackova, J., \& Jasute, E. (2015, July). A global snapshot of computer science education in K-12 schools. In Proceedings of the 2015 ITiCSE on Working Group Reports, 65-83.

Indiana Department of Education. (2019, January 11). Workforce STEM/Computer Science.

Retrieved from https://www.doe.in.gov/wf-stem/computer-science

K-12 Computer Science Framework (2016). Framework view by grade band. Retrieved from

http://www.k12cs.org

Massachusetts Department of Elementary and Secondary Education (2016). 2016

Massachusetts Digital Literacy and Computer Science (DLCS) Curriculum Framework. Retrieved from: http://www.doe.mass.edu/frameworks/dlcs.pdf

Ozogul, G., Karlin, M., \& Ottenbreit-Leftwich, A. (2018). Preservice Teacher Computer 
Instructional Practices for Addressing Computer Science Standards: Using Computer Kits in Preservice Teacher Education

Ozogul, Karlin, Ottenbreit-Leftwich, Ding, Liao, Guo

Science Preparation: A Case Study of an Undergraduate Computer Education Licensure Program. Journal of Technology and Teacher Education, 26(3), 375-409.

Saldaña, J. (2015). The coding manual for qualitative researchers. Thousand Oaks, CA: Sage.

Shulman, L. S. (1986). Those who understand: Knowledge growth in teaching. Educational

researcher, 15(2), 4-14.

The White House (2016). FACT SHEET: President Obama Announces Computer Science for All Initiative. Retrieved from: https://obamawhitehouse.archives.gov/the-press-office/2016/01/30/fact-sheet-president-obama-an-nouncescomputer-science-all-initiative-0

The White House (2017). Presidential Memorandum for the Secretary of Education. Retrieved

from: https:/www.whitehouse.gov/presidential-actions/presidential-memorandum-secretary-education/

Webb, M., Davis, N., Bell, T., Katz, Y. J., Reynolds, N., Chambers, D. P., \& Sysło, M. M.

(2017). Computer science in K-12 school curricula of the 21st century: Why, what and when?. Education and Information Technologies, 22(2), 445-468.

Yadav, A., \& Korb, J. T. (2012). Learning to teach computer science: The need for a methods course. Communications of the ACM, 55(11), 31-33.

Yadav, A., Sands, P., Good, J., \& Lishinki, A. (2018). Computer science and computational thinking in the curriculum: Research and practice. Second Handbook of Information Technology in Primary and Secondary Education, 89-106.

Yin, R. K. (2017). Case study research and applications: Design and methods. (6th ed.). Thousand Oaks, CA: Sage.

\section{Appendix A: Pre-Reflection Form}

Which kit are you working with?

What grade level do you plan on teaching?

What subject area do you plan on teaching?

I feel prepared to teach my future students about computer hardware (e.g., hard drives, motherboards, RAM, etc.) (1-5).

I feel prepared to teach my future students about the basics of computer programming (1-5).

I believe that an activity where students build their own computer would be beneficial in my future classroom (1-5).

Explain why you believe building a computer would be beneficial or not beneficial.

I believe that integrating programming into my future classroom would be beneficial (1-5).

Explain why you believe integrating programming would be beneficial or not beneficial.

Rate your knowledge of programming using block coding languages (e.g., Scratch) (1-5).

Rate your knowledge of programming using non-block coding languages (e.g., PHP) (1-5).

Rate your knowledge of computer hardware (1-5).

Rate your knowledge of building a computer (1-5).

Rate your knowledge for integrating computer programming into your future subject area (1-5).

Rate your paedagogical knowledge for teaching computer programming (i.e., knowing how to teach concepts of computer programming) (1-5).

Enter the last 4 digits of your phone number (to anonymously compare pre- and post-reflections).

\section{Appendix B: Post-Reflection Form}

In addition to pre-reflection questions, these questions were asked:

What characteristics would be important when deciding to use computer kits like these in your future classroom? Please list the two to three most important characteristics you would consider when adapting a similar kit for future use in your classroom.

Explain why you believe building a computer would be beneficial or not beneficial.

Based on your experience working with your kit and the other kit (the one you weren't assigned), which kit do you feel would be more beneficial to use in the classroom? Why?

Would the support resources (e.g., lesson plans) that were provided by your kit's company be beneficial for classroom teachers? Why?

Would you use your assigned computer kit in your future classroom to teach students about block programming (e.g., Scratch)? Why?

Would you use your assigned computer kit in your future classroom to teach students about non-block programming (e.g., PHP)? Why?

Would you use your assigned computer kit in your future classroom to teach students about computer hardware? Why?

Would you use your assigned computer kit in your future classroom to teach students about building a computer? Why? 